Published in final edited form as:

Curr Neurol Neurosci Rep. 2012 April ; 12(2): 165-174. doi:10.1007/s11910-012-0255-x.

\title{
Congenital Myopathies: An Update
}

\author{
Jessica R. Nance, \\ Department of Neurology, Children's National Medical Center, Washington, DC 20010, USA \\ James J. Dowling, \\ Departments of Pediatrics, Neurology, and Neuroscience, University of Michigan Medical Center, \\ Ann Arbor, MI 48109-2200, USA
}

Elizabeth M. Gibbs, and

Departments of Neurology and Neuroscience, University of Michigan Medical Center, Ann Arbor, MI 48109-2200, USA

\section{Carsten G. Bönnemann}

Neuromuscular and Neurogenetic Disorders of Childhood Section, National Institute of Neurological Disorders and Stroke/NIH, Porter Neuroscience Research Center, 35 Convent Drive (Bldg 35), Room 2A-116, Bethesda, MD 20892-3705, USA

Carsten G. Bönnemann: carsten.bonnemann@nih.gov

\section{Abstract}

Congenital myopathy is a clinicopathological concept of characteristic histopathological findings on muscle biopsy in a patient with early-onset weakness. Three main categories are recognized within the classical congenital myopathies: nemaline myopathy, core myopathy, and centronuclear myopathy. Recent evidence of overlapping clinical and histological features between the classical forms and their different genetic entities suggests that there may be shared pathomechanisms between the congenital myopathies. Animal models, especially mouse and zebrafish, have been especially helpful in elucidating such pathomechanisms associated with the congenital myopathies and provide models in which future therapies can be investigated.

\section{Keywords}

Congenital myopathy; Nemaline rod myopathy; Core myopathy; Central core disease; Multiminicore disease; Centronuclear myopathy; ACTA1; NEB; TMP2; TPM3; TNNT1; Cofilin 2; KTBDB13; RYR1; SEPN1; MTM1; DNM2; BIN1

\section{Introduction}

The diagnosis of a congenital myopathy involves a constellation of clinicopathological features typically involving a patient with early-onset weakness together with characteristic histopathological findings on muscle biopsy and normal to slightly elevated creatine

Correspondence to: Carsten G. Bönnemann, carsten.bonnemannenih.gov.

Disclosure No potential conflicts of interest relevant to this article were reported. 
phosphokinase levels. Involvement of the extraocular and/or facial musculature is also common. The three main clinicopathologically defined categories of classical congenital myopathies are nemaline myopathies (NMs), core myopathy, and centronuclear myopathy (CNM). Recent findings suggest that the congenital myopathies are a more diverse group of disorders with varied but overlapping clinical and histologic phenotypes, showing more similarities than anticipated. Increasing evidence suggests that some of the histological features on muscle biopsies can occur on a spectrum that crosses the boundaries of individual genetic entities. Animal models have been especially helpful in elucidating the pathomechanisms of the congenital myopathies. Recent advances suggest that abnormal excitation-contraction coupling may be a common theme in the congenital myopathies, either as a result of malformed contractile filaments in the case of the NMs or disruption of calcium homeostasis at the level of the triad (the smallest functional component of the myofiber that includes the T-tubule and sarcoplasmic reticulum [SR]) in the case of the centronuclear/myotubular and core myopathies.

This review discusses advances leading to this expanded picture of congenital myopathies over the past 3 years, with an emphasis on emerging clinical and histologic phenotypes and genotype-phenotype relationships. We focus on the most common histologic types of congenital myopathies (nemaline, core, and centronuclear), and highlight the broadening spectra of genotypes and overlapping histological phenotypes within each category. We also discuss the recent relevant developments of animal models for elucidating disease mechanisms and preclinical therapeutic possibilities.

\section{Congenital Myopathies with Rods}

In biopsies from patients with NM, the muscle cells contain typical rod-like accumulations of Z-disk-derived material [1]. Rods typically are found in the sarcoplasm but may also be intranuclear [2]. Rod formation has been associated with mutations in skeletal muscle aactin (ACTA1) [3], nebulin (NEB) [4], tropomyosin 3 (TPM3) [5], tropomyosin 2 (TPM2) [6], troponin T1 (TNNT1) [7], cofilin (CLF2) [8], and, most recently, a member of the BTB/ Kelch family of proteins (KBTBD13) (Table 1) [9••].

Clinically, the NMs are subclassified into severe congenital, intermediate congenital, typical congenital, childhood-onset, and adult-onset forms [10]. The typical presentation consists of proximal weakness, respiratory insufficiency, and prominent facial weakness, most often sparing of the extraocular muscles [10]. The clinical phenotype associated with intranuclear rods may be more severe than that associated with sarcoplasmic rods [11•]. Patients with nebulin-related NM may have distal predominant weakness [12]. Also, some of the genes associated with NM have been associated with distal arthrogryposis (TPM2 [13], NEB [14], and TPM3 [15]). There is no association between clinical severity and the number of rods observed in a biopsy [16].

The disease genes associated with NM encode components of the thin filament part of the contractile apparatus, and NMs are thus considered diseases of the thin filament. Overall, they represent diseases in which mutations disrupt the ability of the myofiber to generate adequate force during contraction. While numerous studies have supported these

Curr Neurol Neurosci Rep. Author manuscript; available in PMC 2015 July 05. 
conclusions, the most comprehensive data are provided from recent discoveries in ACTA1related and $N E B$-related congenital myopathies (see below).

\section{ACTA1-Related Myopathies}

Mutations in skeletal muscle a-actin cause primarily sporadic autosomal-dominant NM, and are associated with a range of congenital myopathies that additionally include congenital fiber-type disproportion (CFTD) and core-rod, cap, and zebra body myopathies [3, 11•]. ACTA1 is the primary protein component that polymerizes to form the thin filaments in the functioning myotube [3].

Attempts to establish consistent genotype-phenotype correlations in ACTAl-related myopathies have been largely inconclusive, and mutations associated with classic NM are scattered throughout the gene [11•]. While there is no consistent relationship between the location of ACTA1 mutations and the severity of disease $[11 \bullet, 17,18]$, there is some recent evidence suggesting that mutation location is correlated with histopathological appearance. ACTA1 mutations have been associated with both cytoplasmic and intranuclear rods [11•, 19], while intranuclear rods are most often associated with mutations of p.Val165 [11•]. Mutations that cause CFTD are preferentially found within tropomyosin-interacting sites on the surface of the protein [20]. This is an interesting relationship, given that TPM3 mutations appear to cause CTFD more commonly than NM [20].

Actal transgenic and knock-in mouse models have provided a means for gaining further insight into pathophysiology and possible treatments of ACTAl-related myopathies. Transgenic mouse models of dominant ACTAl mutations show that, as in human disease, increased disease severity is associated with decreased levels of functional protein [21••]. Studies of overexpression of alternate actin isoforms in Actal knockout mice show that cardiac actin [22] but not cytosolic actin [23] is capable of improving the functional phenotype of the Actal knockout mice. Because of an observed association of muscle hypertrophy with milder disease, Actal (His40Tyr) knock-in mice were exposed to hypertrophy-promoting factors (FHL1 and IGF1) and this resulted in increased body weight, improved mobility, and decreased rod pathology [20]. Based on suggestive data from a small clinical cohort study [24], Nguyen et al. [25] examined the effect of L-tyrosine administration to the same knock-in mouse model. Promisingly, the L-tyrosine treatment resulted in improved mobility and decreased rod pathology on muscle biopsy.

\section{NEB-Associated Myopathies}

Mutation in the nebulin gene causes recessively inherited NM [4]. Other than mode of inheritance, $N E B$-related NM is difficult to distinguish from other rod myopathies. While thigh muscle groups are diffusely affected in ACTA1-related myopathies, they are relatively spared in $N E B$-related myopathy [26]. Muscle MRI shows more prominent involvement in the distal lower leg muscles in these patients, especially in the ankle dorsiflexors [26]. There is also evidence for histological overlap between $N E B$-related myopathy and core myopathy,

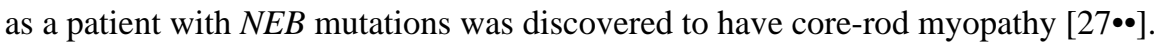
However, the m pattern was similar to that observed in patients with $N E B$-related NM as opposed to patients with core myopathy alone [27••]. 
Studies of myocytes in vitro and vertebrate models provide further insights into the molecular mechanism underlying weakness in $N E B$-associated myopathy. Quantification of nebulin expression in patient biopsies reveals a possible correlation between the quantity of nebulin expression and the severity of disease [14]. Studies of myotubes in vitro suggest that nebulin plays an important role in mediation of actin filament stability [28]. In Neb knockout mice, nebulin-deficient myofibers have decreased thin filament length and decreased generation of maximal tension in the setting of supramaximal calcium levels [29-31]. These findings are in keeping with what has been observed in patient myofibers [32•, 33]. A recently described zebrafish mutant with a recessive nebulin mutation shares the common features observed in both the mouse models of nebulin and patient-derived myotubes [34]. Thus, it seems that nebulin absence/deficiency leads to shortened thin filaments resulting in defective cross-bridge kinetics and submaximal force generation during muscle contraction.

\section{Other Rod Myopathies}

Recent discoveries of two new genes causing NM highlight an expanding understanding of the overlap between different histological subtypes within the congenital myopathies. The most recent genetic discovery in NM are mutations in KBTBD13 causing a dominant rod myopathy with cores $[9 \bullet \bullet$, referred to as NM type 6 . This myopathy is characterized by childhood-onset of slowly progressive weakness of neck and proximal muscle groups, and a slowness of movement that is not common in other congenital myopathies [35]. This slowness of movement, together with core-like structures, may represent a sign of abnormal excitation-contraction coupling. Muscle biopsies show softly defined core areas referred to as "pseudocores" [35], distinct from the sharply demarcated core structures observed in RYRI mutations [36, 37] and NEB mutations [27••]. The exact role of KBTBD13 is unknown, but other BTB/Kelch family proteins are involved in regulation of cytoskeleton remodeling, gene transcription, and myofiber assembly [9••].

Mutations in the cofilin gene cause a recessive myopathy with both minicores and rods [8]. The $C F L 2$ gene encodes a protein that influences actin dynamics though interaction with tropomyosin [38]. Two siblings were described with hypotonia at birth, delayed motor milestones, and inability to run [8]. In contrast to classical NM, these patients have no involvement of facial muscles or distal leg weakness [8].

Together, the identification of $C F L 2$ and $K B T B D 13$ mutations in rod myopathy with cores underscores the growing and overlapping list of gene mutations associated with both cores and rods. This list additionally includes ACTAl [39], NEB [27••], and RYRl [36, 37, 40], and suggests the possibility of shared pathomechanisms between the rod and core myopathies. The common pathomechanisms are unknown at this time, but may represent defects in excitation-contraction coupling.

\section{Myopathies with Cores}

The core myopathies are characterized by the histopathological finding of areas lacking histochemical oxidative and glycolytic enzymatic activity reflecting an absence of mitochondria [41, 42]. Cores are called unstructured if they contain accumulations of disorganized myofibrillar material. They are referred to as either central cores (running the

Curr Neurol Neurosci Rep. Author manuscript; available in PMC 2015 July 05. 
length of the myofiber) or minicores (short zones of myofibrillar disorganization that are wider then they are long on a longitudinal section) [41, 42]. Based on these features, patients with core myopathy are traditionally subclassified as having either central core disease (CCD) or multiminicore disease, although this distinction may sometimes be blurred. Clinically, these myopathies manifest with proximal muscle weakness with onset congenitally, in infancy, or in early childhood [43,44]. Less commonly, there may be bulbar and facial weakness [44]. Core myopathy is thought to be the most common congenital myopathy [45•], but may still be under-recognized because the characteristic histopathological changes may not be present on biopsies at an early age. The genes associated with core myopathies are presented in Table 1.

\section{RYR1-Related Core Myopathies}

Myopathies with cores are most commonly associated with mutations in the RYRl gene [46], which encodes the skeletal muscle ryanodine receptor. RyR1 is a ligand-gated calcium channel located on the SR, where it functions as a critical regulator of calcium homeostasis and as the channel required for excitation-dependent calcium release during excitationcontraction coupling. Central cores related to RYRI mutations are usually identified in type I fibers and the muscle biopsy often shows significant fibroadipose tissue [47]. RYR1 related cores may be described as structured or unstructured depending on the pattern of ATPase activity and the degree of myofibrillary disorganization demonstrated by electron microscopy [44].

Core myopathies caused by RYR1 mutations can be dominant or recessive. Autosomaldominant and de novo mutations are usually associated with CCD, and characterized clinically by infantile-onset of static or slowly progressive proximal weakness involving hip and axial muscles [44]. Skeletal deformities are common and may include hip dislocation and foot deformities [48]. Bulbar weakness and respiratory compromise are rare features [38]. Of note, there is a wide range of clinical presentations, especially in relation to age of onset [49].

Historically, dominantly acting mutations in the $R Y R I$ gene causing core myopathies localized more commonly to the $\mathrm{C}$-terminal domain of the gene, which encodes the transmembrane and luminal portion of the channel [46], while RYR1 mutations causing malignant hyperthermia (MH) were usually located in the $\mathrm{N}$-terminal and central regions of protein [50]. However, while this genotype-phenotype correlation still holds true for $\mathrm{MH}$, recent data suggest that dominant CCD mutations in RYRI span the length of the gene [49]. Of note, de novo dominant mutations have also been described in individuals with core-rod myopathy [40].

Mutations causing recessive $R Y R 1$-related myopathy appear to be distributed over the entire sequence of the RYRl gene [51]. Histologically, recessive RYRI mutations are often associated with multiminicores, which are shorter than classical central cores, lack myofibrillary organization, and are seen in both type I and type II muscle fibers [51, 52]. Recessive mutations are also seen with other histological findings including central nuclei and CFTD [53••, 54]. 
Recently, Wilmshurst et al. [53・•] described a series of 17 patients with RYRI mutations and central nuclei on muscle biopsy. Inheritance was autosomal recessive in the majority of patients. There was early infantile presentation with hypotonia and weakness followed by progressive clinical improvement. Extraocular eye muscle involvement was also a prominent feature. Muscle biopsies from all of the patients manifested nuclear centralization/internalization without the presence of central cores commonly associated with RYRI mutations. Interestingly, two-thirds of patients demonstrated central cores or minicores on biopsies performed later in life [53••]. An additional seven patients with RYRIrelated myopathy were described with prominent central nuclei on histopathology [55•]. These patients, particularly those biopsied at older ages, also demonstrated large areas of sarcomeric disorganization on muscle biopsy [55•]. Thus, cores or other core-like areas may develop over time in patients with $R Y R I$-related CNM, emphasizing yet another histopathological continuum.

Histological findings may also depend on the muscle sampled, as there is evidence for striking differential muscle involvement in the RYRI-related myopathies. Muscle MRI showed relative sparing of the rectus femoris regardless of mode of inheritance and histopathologic subtype [56], and may represent a tool for early diagnosis of myopathies related to RYRI mutations. Additional evidence suggests that the gradient of distribution and severity of muscle involvement on muscle MRI may be helpful in differentiating dominant RYRI-related disease from recessive RYR1-related disease without ophthalmoparesis [57].

RYRl-related myopathies are thought to result from abnormal excitation-contraction coupling secondary to impaired calcium release in the setting of a defective ryanodine receptor calcium channel. How this defect is related to the histological development of core structures remains unclear. The development of cores was recently studied in an Ryrl ${ }^{Y 522 S / W T}$ mouse model with MH and mild core myopathy [58]. This mouse had progressive core development with localized mitochondrial damage and subsequent disruption of nearby SR and T-tubule structures, followed by development of early cores with absent mitochondria and shortened sarcomeres [58]. Disruption of the T-tubule system is commonly observed in both core myopathies and centronuclear/myotubular myopathies, which may explain why both cores and central nuclei may be observed in patients with RYR1 mutations [53••, 58].

A second knock-in mouse models the common and clinically severe CCD mutation p.Ile4898Thr [59•]. Histologically, the diseased mouse muscle undergoes transition from minicores to central cores and rods [59•]. Interestingly, this mutation was recently observed in patients with severe core-rod myopathy [40]. Therefore, additional study of this model may provide key insight into overlap between rod and core myopathies.

\section{SEPN1-Related Core Myopathies}

SEPN1 encodes selenoprotein N1, a member of the selenocysteine-containing protein family, which may play a role in intracellular calcium homeostasis and protection against redox-related cellular damage [60]. SEPNI gene mutations are associated with multiminicores, which are typically smaller in size than those associated with recessive RYRI mutations [47], although there is a large histological spectrum associated with SEPNI 
mutations that also includes nonspecific myopathic changes, CFTD, and Mallory body-like inclusions [61, 62]. Scoto et al. [63] describe a large case series of patients with SEPN1related myopathies. Clinically, patients with $S E P N 1$-related disease manifest with a predominantly axial myopathy with weak neck flexors, spinal rigidity, and scoliosis, as well as prominent respiratory compromise disproportionate to their extremity weakness. The respiratory compromise may be progressive even while limb weakness remains relatively mild and static. The majority of these patients achieve and maintain independent ambulation. Bulbar weakness is reported while extraocular muscle involvement does not seem to occur [63]. There is no relationship between morphological pattern of minicores and the type or localization of SEPN1 mutations [64].

Studies in zebrafish and human muscle demonstrate that SepN1 interacts closely with the RyR1and is thereby involved in the regulation of intracellular calcium homeostasis [65]. A mouse Sepnl knockout model, while not expressly recapitulating the weakness and histopathology of the human disease, is likely to provide a system for further exploration of the pathogenesis of SEPN1 mutations [66].

\section{Myopathies with Central Nuclei}

CNMs are characterized by excessive internalized/centralized nuclei within myofibers on muscle biopsy without prominent findings of degeneration or regeneration. There may be abnormal patterns on NADH-TR staining, which can be helpful in differentiating different subtypes of CNM. Clinically, the age of onset and pattern of weakness vary depending on the gene involved and the specific mutation. As with the congenital myopathies discussed earlier, there is increasing evidence of histological overlap and recent studies in animal models that have helped to clarify the underlying molecular mechanisms. Genes associated with CNM are summarized in Table 1.

\section{MTM1-Related Centronuclear Myopathy}

$\mathrm{X}$-linked CNM or myotubular myopathy is caused by a mutation in the MTM1 gene coding for myotubularin, a member of the phosphoinositide phosphatase protein family [67]. Phosphoinositides and their regulatory enzymes are primarily involved in the trafficking of membranes and vesicles between subcellular organelle membranes [68].

Myotubular myopathy most commonly presents with severe symptoms starting from birth [69]. Affected male neonates are profoundly hypotonic and weak with significant respiratory failure and feeding problems, often resulting in early mortality. External ophthalmoplegia is common, although it may not be noticeable at birth [69]. Surviving individuals have significant morbidity, including lifelong wheelchair and ventilator dependence. A minority of boys with MTM1 mutations have a more mild clinical presentation [69]. Mutations are found throughout the gene, and there is limited correlation between genotype and phenotype [70]. However, a few mutations have been observed to cause milder symptomatology [70, 71]. Female carriers are usually asymptomatic, although there are rare reports of unfavorably skewed X-inactivation leading to a severe infantile form [72] or a mild adultonset form in females [73]. 
The histopathology of myotubular myopathy has been reviewed by Romero [74]. Myofibers show single, very central nuclei within round fibers, often with a dark central region surrounded by a pale peripheral halo on NADH-TR staining [74]. In muscles of patients with the milder and more slowly progressive forms of $M T M 1$-associated myopathy, necklace fibers, which appear as a basophilic ring of internalized, but not necessarily centralized, nuclei aligned beneath the sarcolemma, are a fairly distinct feature [75•].

Recent advances from the study of animal models for myotubular myopathy have provided insight into the molecular mechanism of the disease and have opened avenues for the development of effective treatments. A zebrafish model of myotubular myopathy recapitulated the salient aspects of the human disease and, importantly, identified structural and functional abnormalities in the T-tubule/terminal SR (triad) system [76••]. This study additionally uncovered triad abnormalities in biopsies from patients with MTM1 mutations. Subsequently, the observations of structural and functional abnormalities in the triad, including defective excitation-contraction coupling and altered calcium homeostasis, have been demonstrated and expanded upon in both murine and canine models of myotubular myopathy $[64,77,78,79 \bullet \cdot$. These studies have led to a conclusion that a major aspect of disease from MTM1 mutations is due to abnormalities in the excitation-contraction coupling machinery. This pathology is likely caused by the loss of myotubularin function at the triad, as several studies have demonstrated its localization to this structure, although the exact pathomechanisms are still under investigation [64, 76••, 78].

Additional studies using the murine knockout model and the zebrafish model of myotubular myopathy have suggested new avenues for therapy development. Buj-Bello et al. [78] have successfully demonstrated rescue of both histopathologic abnormalities as well as muscle functional properties by adeno-associated virus-mediated re-expression of $M T M 1$, revealing the potential efficacy of gene therapy for the disease. A separate study by Lawlor et al. [80] showed that treatment with an activin inhibitor improves muscle strength and prolongs lifespan of the Mtml knockout mice. Lastly, exposure of the zebrafish myotubular myopathy model to an acetylcholinesterase inhibitor resulted in significantly improved movement [81••]. This, in combination with a case report describing clinical features of a neuromuscular disorder and qualitative improvement with pyridostigmine in a patient with myotubular myopathy $[81 \bullet \cdot$, suggests that augmentation of neuromuscular junction function may be an additional viable treatment strategy.

\section{DMN2-Related Centronuclear Myopathy}

A subset of individuals with dominant CNM possess mutations in the DNM2 gene [82]. $D N M 2$ encodes the dynamin-2 protein, a large GTPase involved in membrane traffic, endocytosis, and interaction with the actin and microtubule filamentous networks [83]. Clinical forms of DNM2-related CNM range between mild onset in late childhood or adulthood and severe, early onset [82, 84-86]. Characteristic muscle involvement includes facial and extraocular muscle weakness, and ptosis is frequently present [87]. Extremity weakness is often diffuse, although MRI studies show more prominent involvement of the distal limbs in many patients $[88,89]$. In terms of genotype-phenotype correlations, mutations causing severe disease are most commonly found in the pleckstrin-homology and 
GTPase effector domains, while more mild disease is associated with middle domain mutations [90].

The characteristic pathology of $D M N 2$-related myopathy has also been reviewed by Romero [74]. Muscle fibers demonstrate nuclear centralization and, to a lesser degree, nuclear internalization. A characteristic histopathological feature of DNM2 mutations is strands radiating from the central nucleus, which are identified with NADH-TR staining on transverse sections. Type I myofiber predominance and hypotrophy are also commonly observed.

Although the specific pathomechanisms underlying DNM2-related CNM are still unknown, recent studies have provided insight into the molecular basis of the disease. Two in vitro studies found that CNM-causing mutations can increase Dyn2 GTPase activity and alter the self-assembly properties of Dyn2 polymers [91, 92]. In a knock-in mouse model of DNM2related CNM, subtle alterations in triad organization were reported and there was a significant increase in basal cytosolic calcium [93]. Similarly, Cowling et al. [94] showed that viral overexpression of mutant Dyn2 in mouse muscle causes substantial T-tubule disorganization resembling the changes seen in models of myotubular myopathy. Unlike MTM1, Dyn2 does not appear to localize to the triad [93, 94], and the relationship between Dyn2 function and triad architecture is still unclear.

\section{BIN1-Related Centronuclear Myopathy}

Amphiphysin 2-related CNM is a comparatively rare form of CNM. It is associated with mutations in the BINl gene encoding the protein amphiphysin 2, which binds to DNM2 during clathrin-mediated endocytosis [95]. Clinical features include marked facial weakness, prominent masticatory weakness, external ophthalmoplegia, ptosis, and proximal muscle weakness [96].

Several studies have shown that a muscle-specific iso-form of amphiphysin 2 is important for T-tubule biogenesis [97, 98]. In the initial characterization of BIN1-related CNM, Nicot et al. [99] demonstrated that expression of mutant protein disrupted tubule formation in an ex vivo model of T-tubule biogenesis. Amphiphysin 2 localization and triad architecture have been shown to be altered in muscle from patients with MTM1, DNM2, and BIN1 mutations, as well as the mouse knockout model for Mtml [100••]. Thus, a potential common mechanism emerges with the known genetic causes of CNM involved in the disruption of triad formation and thus the mediation of excitation-contraction coupling. This then also establishes a pathophysiological link between the centronuclear and core myopathies that is reflected in the shared histological features seen in some RYR1-related myopathies.

\section{Conclusions}

Congenital myopathies are a group of muscle disorders largely defined by their histopathological appearance, but more recently have been expanded to include varied and overlapping phenotypes as well as genotypes where a single histological appearance can be caused by mutations in multiple genes and mutations in a single gene can result in multiple 
phenotypic and histological presentations. In addition, distinct histopathological features, once thought to be defining for a given subtype, can be observed in the same patient associated with variable genetic diagnoses. These overlapping histopathological features reinforce the concept of overlapping pathophysiological mechanisms. Disruption of excitation-contraction coupling and control of the skeletal muscle contractile apparatus are now emerging as the most important pathophysiological consequences in the majority of the common subtypes. Animal models, especially zebra-fish and mouse knockout models, have been crucial in generating this broader understanding of the molecular pathophysiology and will provide excellent models for understanding more about genotype-phenotype relationships and the development of new treatments.

\section{Acknowledgments}

CGB's research is supported by the Intramural Research Program of the National Institute of Neurological Disorders and Stroke, National Institutes of Health, JD is supported by an NIH K08 award (NIH1K08AR054835). We apologize to researchers whose work could not be cited due to this reviews restrictions in length and focus.

\section{References}

Papers of particular interest, published recently, have been highlighted as:

- Of importance

•• Of major importance

1. Gonatas NK. The fine structure of the rod-like bodies in nemaline myopathy and their relation to the Z-discs. J Neuropathol Exp Neurol. 1966; 25:409-21. [PubMed: 5946176]

2. Goebel HH, Warlo I. Nemaline myopathy with intranuclear rods-intranuclear rod myopathy. Neuromuscul Disord. 1997; 7:13-9. [PubMed: 9132135]

3. Nowak KJ, Wattanasirichaigoon D, Goebel HH, et al. Mutations in the skeletal muscle alpha-actin gene in patients with actin myopathy and nemaline myopathy. Nat Genet. 1999; 23:208-12. [PubMed: 10508519]

4. Pelin K, Hilpela P, Donner K, et al. Mutations in the nebulin gene associated with autosomal recessive nemaline myopathy. Proc Natl Acad Sci USA. 1999; 96:2305-10. [PubMed: 10051637]

5. Laing NG, Wilton SD, Akkari PA, et al. A mutation in the alpha tropomyosin gene TPM3 associated with autosomal dominant nemaline myopathy. Nat Genet. 1995; 9:75-9. [PubMed: 7704029]

6. Donner K, Ollikainen M, Ridanpaa M, et al. Mutations in the beta-tropomyosin (TPM2) gene-a rare cause of nemaline myopathy. Neuromuscul Disord. 2002; 12:151-8. [PubMed: 11738357]

7. Johnston JJ, Kelley RI, Crawford TO, et al. A novel nemaline myopathy in the Amish caused by a mutation in troponin T1. Am J Hum Genet. 2000; 67:814-21. [PubMed: 10952871]

8. Agrawal PB, Greenleaf RS, Tomczak KK, et al. Nemaline myopathy with minicores caused by mutation of the CFL2 gene encoding the skeletal muscle actin-binding protein, cofilin-2. Am J Hum Genet. 2007; 80:162-1677. [PubMed: 17160903]

9 •. Sambuughin N, Yau KS, Olive M, et al. Dominant mutations in KBTBD13, a member of the BTB/Kelch family, cause nemaline myopathy with cores. Am J Hum Genet. 2010; 87:842-7. This article describes the identification of a new gene associated with NM with both rods and cores, known as NM type 6. [PubMed: 21109227]

10. Ryan MM, Schnell C, Strickland CD, et al. Nemaline myopathy: a clinical study of 143 cases. Ann Neurol. 2001; 50:312-20. [PubMed: 11558787]

11 • Laing NG, Dye DE, Wallgren-Pettersson C, et al. Mutations and polymorphisms of the skeletal muscle alpha-actin gene (ACTA1). Hum Mutat. 2009; 30:1267-77. This established the first 
large database describing ACTA1 mutations. Evaluation of this data is important for the delineation of emerging genotype-phenotype relationships. [PubMed: 19562689]

12. Wallgren-Pettersson C, Lehtokari VL, Kalimo H, et al. Distal myopathy caused by homozygous missense mutations in the nebulin gene. Brain. 2007; 130:1465-76. [PubMed: 17525139]

13. Sung SS, Brassington AM, Grannatt K, et al. Mutations in genes encoding fast-twitch contractile proteins cause distal arthrogryposis syndromes. Am J Hum Genet. 2003; 72:681-90. [PubMed: 12592607]

14. Lawlor MW, Ottenheijm CA, Lehtokari VL, et al. Novel mutations in NEB cause abnormal nebulin expression and markedly impaired muscle force generation in severe nemaline myopathy. Skelet Muscle. 2011; 1:23. http://www.skeletalmusclejournal.com/. [PubMed: 21798101]

15. Monnier N, Lunardi J, Marty I, et al. Absence of beta-tropomyosin is a new cause of Escobar syndrome associated with nemaline myopathy. Neuromuscul Disord. 2009; 19:118-23. [PubMed: 19155175]

16. Shimomura C, Nonaka I. Nemaline myopathy: comparative muscle histochemistry in the severe neonatal, moderate congenital, and adult-onset forms. Pediatr Neurol. 1989; 5:25-31. [PubMed: 2712935]

17. Ilkovski B, Cooper ST, Nowak K, et al. Nemaline myopathy caused by mutations in the muscle alpha-skeletal-actin gene. Am J Hum Genet. 2001; 68:1333-43. [PubMed: 11333380]

18. Feng JJ, Marston S. Genotype-phenotype correlations in ACTA1 mutations that cause congenital myopathies. Neuromuscul Disord. 2009; 19:6-16. [PubMed: 18976909]

19. Ravenscroft G, Wilmshurst JM, Pillay K, et al. A novel ACTA1 mutation resulting in a severe congenital myopathy with nemaline bodies, intranuclear rods and type I fibre predominance. Neuromuscul Disord. 2011; 21:31-6. [PubMed: 20850316]

20. Laing NG, Wallgren-Pettersson C. 161st ENMC International Workshop on nemaline myopathy and related disorders, Newcastle upon Tyne, 2008. Neuromuscul Disord. 2009; 19:300-5. [PubMed: 19264483]

21••. Ravenscroft G, Jackaman C, Bringans S, et al. Mouse models of dominant ACTA1 disease recapitulate human disease and provide insight into therapies. Brain. 2011; 134:1101-15. This describes the development of two transgenic ACTA1 mouse models, one with severe disease and another with moderate disease, which demonstrate that the severity of ACTA1-related myopathy may be dependent on the amount of mutant protein expressed. [PubMed: 21303860]

22. Nowak KJ, Ravenscroft G, Jackaman C, et al. Rescue of skeletal muscle alpha-actin-null mice by cardiac (fetal) alpha-actin. J Cell Biol. 2009; 185:903-15. [PubMed: 19468071]

23. Jaeger MA, Sonnemann KJ, Fitzsimons DP, et al. Context-dependent functional substitution of alpha-skeletal actin by gamma-cytoplasmic actin. FASEB J. 2009; 23:2205-14. [PubMed: 19279140]

24. Ryan MM, Sy C, Rudge S, et al. Dietary L-tyrosine supplementation in nemaline myopathy. J Child Neurol. 2008; 23:609-13. [PubMed: 18079309]

25. Nguyen MA, Joya JE, Kee AJ, et al. Hypertrophy and dietary tyrosine ameliorate the phenotypes of a mouse model of severe nemaline myopathy. Brain. 2011; 134:3513-26.

26. Jungbluth H, Sewry CA, Counsell S, et al. Magnetic resonance imaging of muscle in nemaline myopathy. Neuromuscul Disord. 2004; 14:779-84. [PubMed: 15564032]

27••. Romero NB, Lehtokari VL, Quijano-Roy S, et al. Core-rod myopathy caused by mutations in the nebulin gene. Neurology. 2009; 73:1159-61. This is a description of a patient with nebulinrelated myopathy with rods and cores, which on muscle biopsy represents a novel association between gene mutation and overlapping histopathological phenotypes. [PubMed: 19805734]

28. Chen MJ, Shih CL, Wang K. Nebulin as an actin zipper. A two-module nebulin fragment promotes actin nucleation and stabilizes actin filaments. J Biol Chem. 1993; 268:20327-34. [PubMed: 8376391]

29. Witt CC, Burkart C, Labeit D, et al. Nebulin regulates thin filament length, contractility, and Zdisk structure in vivo. EMBO J. 2006; 25:3843-55. [PubMed: 16902413]

30. Bang ML, Li X, Littlefield R, et al. Nebulin-deficient mice exhibit shorter thin filament lengths and reduced contractile function in skeletal muscle. J Cell Biol. 2006; 173:905-16. [PubMed: 16769824] 
31. Chandra M, Mamidi R, Ford S, et al. Nebulin alters cross-bridge cycling kinetics and increases thin filament activation: a novel mechanism for increasing tension and reducing tension cost. J Biol Chem. 2009; 284:30889-96. [PubMed: 19736309]

32. Ottenheijm CA, Hooijman P, DeChene ET, et al. Altered myo-filament function depresses force generation in patients with nebulin-based nemaline myopathy (NEM2). J Struct Biol. 2009; 170:334-43. This study of muscle from patients with nebulin-related NM demonstrates that mutation of nebulin alters thin filament length and alters contraction kinetics resulting in decreased force generation. [PubMed: 19944167]

33. Ottenheijm CA, Witt CC, Stienen GJ, et al. Thin filament length dysregulation contributes to muscle weakness in nemaline myopathy patients with nebulin deficiency. Hum Mol Genet. 2009; 18:2359-69. [PubMed: 19346529]

34. Telfer WR, Nelson DD, Waugh T, et al. neb: a zebrafish model of nemaline myopathy due to nebulin mutation. Dis Model Mech. 2011 In press.

35. Olive M, Goldfarb LG, Lee HS, et al. Nemaline myopathy type 6: clinical and myopathological features. Muscle Nerve. 2010; 42:901-7. [PubMed: 21104864]

36. Monnier N, Romero NB, Lerale J, et al. An autosomal dominant congenital myopathy with cores and rods is associated with a neomutation in the RYR1 gene encoding the skeletal muscle ryanodine receptor. Hum Mol Genet. 2000; 9:2599-608. [PubMed: 11063719]

37. Scacheri PC, Hoffman EP, Fratkin JD, et al. A novel ryanodine receptor gene mutation causing both cores and rods in congenital myopathy. Neurology. 2000; 55:1689-96. [PubMed: 11113224]

38. Ono S, Ono K. Tropomyosin inhibits ADF/cofilin-dependent actin filament dynamics. J Cell Biol. 2002; 156:1065-76. [PubMed: 11901171]

39. Kaindl AM, Ruschendorf F, Krause S, et al. Missense mutations of ACTA1 cause dominant congenital myopathy with cores. J Med Genet. 2004; 41:842-8. [PubMed: 15520409]

40. Hernandez-Lain A, Husson I, Monnier N, et al. De novo RYR1 heterozygous mutation (I4898T) causing lethal core-rod myopathy in twins. Eur J Med Genet. 2011; 54:29-33. [PubMed: 20888934]

41. Dubowitz V, Pearse AG. Oxidative enzymes and phosphorylase in central-core disease of muscle. Lancet. 1960; 2:23-4. [PubMed: 13818365]

42. Dubowitz V, Roy S. Central core disease of muscle: clinical, histochemical and electron microscopic studies of an affected mother and child. Brain. 1970; 93:133-46. [PubMed: 5418397]

43. Engel WK, Foster JB, Hughes BP, et al. Central core disease-an investigation of a rare muscle cell abnormality. Brain. 1961; 84:167-85. [PubMed: 13696813]

44. Jungbluth H. Central core disease. Orphanet J Rare Dis. 2007; 2:25. http://www.ojrd.com/content/. [PubMed: 17504518]

45•. Amburgey K, McNamara N, Bennett LR, et al. Prevalence of congenital myopathies in a representative pediatric united states population. Ann Neurol. 2011; 70:662-5. The study shows a similar prevalence of congenital myopathies in Southwestern Michigan compared to previous studies of patients in Sweden and Northern Ireland. It identifies centronuclear myopathies as the most common identifiable pathological subtype of congenital myopathies. [PubMed: 22028225]

46. Wu S, Ibarra MC, Malicdan MC, et al. Central core disease is due to RYR1 mutations in more than 90\% of patients. Brain. 2006; 129:1470-80. [PubMed: 16621918]

47. Sewry CA, Muller C, Davis M, et al. The spectrum of pathology in central core disease. Neuromuscul Disord. 2002; 12:930-8. [PubMed: 12467748]

48. Gamble JG, Rinsky LA, Lee JH. Orthopaedic aspects of central core disease. J Bone Joint Surg Am. 1988; 70:1061-6. [PubMed: 3403575]

49. Jungbluth, H.; Dowling, JJ.; Ferreiro, A., et al. Neuromuscul Disord; 182nd ENMC International Workshop: RYR1-related myopathies; 15-17th April 2011; Naarden, The Netherlands. 2012. In press

50. Sei Y, Sambuughin NN, Davis EJ, et al. Malignant hyperthermia in North America: genetic screening of the three hot spots in the type I ryanodine receptor gene. Anesthesiology. 2004; 101:824-30. [PubMed: 15448513]

51. Jungbluth H, Muller CR, Halliger-Keller B, et al. Autosomal recessive inheritance of RYR1 mutations in a congenital myopathy with cores. Neurology. 2002; 59:284-7. [PubMed: 12136074]

Curr Neurol Neurosci Rep. Author manuscript; available in PMC 2015 July 05. 
52. Jungbluth H, Zhou H, Hartley L, et al. Minicore myopathy with ophthalmoplegia caused by mutations in the ryanodine receptor type 1 gene. Neurology. 2005; 65:1930-5. [PubMed: 16380615]

53••. Wilmshurst JM, Lillis S, Zhou H, et al. RYR1 mutations are a common cause of congenital myopathies with central nuclei. Ann Neurol. 2010; 68:717-26. This article shows that patients with RYR1 mutations have central nuclei on muscle biopsy especially early in the disease course. When biopsied later in life, many of these patients had developed cores. Overall, this supports that histopathological changes occur on a continuum and that the timing and location of muscle biopsy are important factors in diagnosis. [PubMed: 20839240]

54. Clarke NF, Waddell LB, Cooper ST, et al. Recessive mutations in RYR1 are a common cause of congenital fiber type disproportion. Hum Mutat. 2010; 31:E1544-50. [PubMed: 20583297]

55•. Bevilacqua JA, Monnier N, Bitoun M, et al. Recessive RYR1 mutations cause unusual congenital myopathy with prominent nuclear internalization and large areas of myofibrillar disorganization. Neuropathol Appl Neurobiol. 2011; 37:271-84. This is a second case series confirming that RYR1 mutations may be associated with central nuclei on muscle biopsy early in the disease course. Later muscle biopsies in some of these patients revealed core-like structures. [PubMed: 21062345]

56. Jungbluth H, Davis MR, Muller C, et al. Magnetic resonance imaging of muscle in congenital myopathies associated with RYR1 mutations. Neuromuscul Disord. 2004; 14:785-90. [PubMed: 15564033]

57. Klein A, Jungbluth $\mathrm{H}$, Clement E, et al. Muscle magnetic resonance imaging in congenital myopathies due to ryanodine receptor type 1 gene mutations. Arch Neurol. 2011; 68:1171-9. [PubMed: 21911697]

58. Boncompagni S, Rossi AE, Micaroni M, et al. Characterization and temporal development of cores in a mouse model of malignant hyperthermia. Proc Natl Acad Sci USA. 2009; 106:21996-2001. [PubMed: 19966218]

59•. Zvaritch E, Kraeva N, Bombardier E, et al. Ca2+ dysregulation in Ryr1(I4895T/wt) mice causes congenital myopathy with progressive formation of minicores, cores, and nemaline rods. Proc Natl Acad Sci USA. 2009; 106:21813-8. This article demonstrates that histopathological findings of minicores, cores, and rods occur on a continuum in this transgenic mouse model of RYR1-related myopathy. [PubMed: 19959667]

60. Arbogast S, Ferreiro A. Selenoproteins and protection against oxidative stress: selenoprotein N as a novel player at the crossroads of redox signaling and calcium homeostasis. Antioxid Redox Signal. 2009; 12:893-904. [PubMed: 19769461]

61. Schara U, Kress W, Bonnemann CG, et al. The phenotype and long-term follow-up in 11 patients with juvenile selenoprotein N1-related myopathy. Eur J Paediatr Neurol. 2008; 12:224-30. [PubMed: 17951086]

62. Ferreiro A, Ceuterick-de Groote C, Marks JJ, et al. Desmin-related myopathy with Mallory bodylike inclusions is caused by mutations of the selenoprotein N gene. Ann Neurol. 2004; 55:676-86. [PubMed: 15122708]

63. Scoto M, Cirak S, Mein R, et al. SEPN1-related myopathies: clinical course in a large cohort of patients. Neurology. 2011; 76:2073-8. [PubMed: 21670436]

64. Jungbluth H, Wallgren-Pettersson C, Laporte JF. 164th ENMC International workshop: 6th workshop on centronuclear (myotubular) myopathies, 16-18th January 2009, Naarden, The Netherlands. Neuromuscul Disord. 2009; 19:721-9. [PubMed: 19683444]

65. Jurynec MJ, Xia R, Mackrill JJ, et al. Selenoprotein N is required for ryanodine receptor calcium release channel activity in human and zebrafish muscle. Proc Natl Acad Sci USA. 2008; 105:12485-90. [PubMed: 18713863]

66. Rederstorff M, Castets P, Arbogast S, et al. Increased muscle stress-sensitivity induced by selenoprotein $\mathrm{N}$ inactivation in mouse: a mammalian model for SEPN1-related myopathy. PLoS One. 2011; 6:e23094. http://www.plosone.org/. [PubMed: 21858002]

67. Laporte J, Hu LJ, Kretz C, et al. A gene mutated in X-linked myotubular myopathy defines a new putative tyrosine phosphatase family conserved in yeast. Nat Genet. 1996; 13:175-82. [PubMed: 8640223] 
68. Shen D, Wang X, Xu H. Pairing phosphoinositides with calcium ions in endolysosomal dynamics: phosphoinositides control the direction and specificity of membrane trafficking by regulating the activity of calcium channels in the endolysosomes. Bioessays. 2011; 33:448-57. [PubMed: 21538413]

69. Herman GE, Kopacz K, Zhao W, et al. Characterization of mutations in fifty North American patients with X-linked myotubular myopathy. Hum Mutat. 2002; 19:114-21. [PubMed: 11793470]

70. Biancalana V, Caron O, Gallati S, et al. Characterisation of mutations in 77 patients with X-linked myotubular myopathy, including a family with a very mild phenotype. Hum Genet. 2003; 112:135-42. [PubMed: 12522554]

71. Tsai TC, Horinouchi H, Noguchi S, et al. Characterization of MTM1 mutations in 31 Japanese families with myotubular myopathy, including a patient carrying $240 \mathrm{~kb}$ deletion in Xq28 without male hypogenitalism. Neuromuscul Disord. 2005; 15:245-52. [PubMed: 15725586]

72. Jungbluth H, Sewry CA, Buj-Bello A, et al. Early and severe presentation of X-linked myotubular myopathy in a girl with skewed X-inactivation. Neuromuscul Disord. 2003; 13:55-9. [PubMed: 12467733]

73. Kristiansen M, Knudsen GP, Tanner SM, et al. X-inactivation patterns in carriers of X-linked myotubular myopathy. Neuromuscul Disord. 2003; 13:468-71. [PubMed: 12899873]

74. Romero NB. Centronuclear myopathies: a widening concept. Neuromuscul Disord. 2010; 20:2238. [PubMed: 20181480]

75•. Bevilacqua JA, Bitoun M, Biancalana V, et al. "Necklace" fibers, a new histological marker of late-onset MTM1-related centronuclear myopathy. Acta Neuropathol. 2009; 117:283-91. This article describes a new clinical and pathological phenotype of myotubular myopathy with sporadic, late onset and finding of necklace fibers on biopsy in male and female patients. [PubMed: 19084976]

76. Dowling JJ, Vreede AP, Low SE, et al. Loss of myotubularin function results in T-tubule disorganization in zebrafish and human myotubular myopathy. PLoS Genet. 2009; 5:e1000372. http://www.plosone.org/. This zebrafish model mimics human disease and shows that myotubularin is essential in establishing the architecture of the T-tubule, thereby causing defective calcium release from the sarcoplasmic and disrupting excitation-contraction coupling. Along with the MTM1 knockout mouse, this represents a useful animal model of myotubular myopathy. $\bullet$. [PubMed: 19197364]

77. Tiret L, Blot S, Kessler JL, et al. The cnm locus, a canine homologue of human autosomal forms of centronuclear myopathy, maps to chromosome 2. Hum Genet. 2003; 113:297-306. [PubMed: 12884002]

78. Buj-Bello A, Fougerousse F, Schwab Y, et al. AAV-mediated intramuscular delivery of myotubularin corrects the myotubular myopathy phenotype in targeted murine muscle and suggests a function in plasma membrane homeostasis. Hum Mol Genet. 2008; 17:2132-43. [PubMed: 18434328]

79••. Al-Qusairi L, Weiss N, Toussaint A, et al. T-tubule disorganization and defective excitationcontraction coupling in muscle fibers lacking myotubularin lipid phosphatase. Proc Natl Acad Sci USA. 2009; 106:18763-8. This MTM1 mouse model recapitulates human disease and informs the understanding of the molecular mechanism underlying weakness in myotubular myopathy. Disruption of T-tubule architecture and calcium homeostasis contribute to weakness in myotubular myopathy. [PubMed: 19846786]

80. Lawlor MW, Read BP, Edelstein R, et al. Inhibition of activin receptor type IIB increases strength and lifespan in myotubularin-deficient mice. Am J Pathol. 2011; 178:784-93. [PubMed: 21281811]

$81 \bullet$. Robb SA, Sewry CA, Dowling JJ, et al. Impaired neuromuscular transmission and response to acetylcholinesterase inhibitors in centronuclear myopathies. Neuromuscul Disord. 2011; 21:37986. Treatment of the MTM1 knockdown zebrafish with acetylcholinesterase inhibitors improves spontaneous and provoked movement, likely by potentiating calcium release from the SR. Treatment of several patients with pyridostigmine improved function. [PubMed: 21440438]

82. Bitoun M, Maugenre S, Jeannet PY, et al. Mutations in dynamin 2 cause dominant centronuclear myopathy. Nat Genet. 2005; 37:1207-9. [PubMed: 16227997]

Curr Neurol Neurosci Rep. Author manuscript; available in PMC 2015 July 05. 
83. Durieux AC, Prudhon B, Guicheney P, et al. Dynamin 2 and human diseases. J Mol Med (Berl). 2010; 88:339-50. [PubMed: 20127478]

84. Bitoun M, Bevilacqua JA, Prudhon B, et al. Dynamin 2 mutations cause sporadic centronuclear myopathy with neonatal onset. Ann Neurol. 2007; 62:666-70. [PubMed: 17932957]

85. Bitoun M, Bevilacqua JA, Eymard B, et al. A new centronuclear myopathy phenotype due to a novel dynamin 2 mutation. Neurology. 2009; 72:93-5. [PubMed: 19122038]

86. Koutsopoulos OS, Koch C, Tosch V, et al. Mild functional differences of dynamin 2 mutations associated to centronuclear myopathy and Charcot-Marie Tooth peripheral neuropathy. PLoS One. 2011; 6:e27498. http://www.plosone.org/. [PubMed: 22096584]

87. Fischer D, Herasse M, Bitoun M, et al. Characterization of the muscle involvement in dynamin 2related centronuclear myopathy. Brain. 2006; 129:1463-9. [PubMed: 16585051]

88. Susman RD, Quijano-Roy S, Yang N, et al. Expanding the clinical, pathological and MRI phenotype of DNM2-related centronuclear myopathy. Neuromuscul Disord. 2010; 20:229-37. [PubMed: 20227276]

89. Schessl J, Medne L, Hu Y, et al. MRI in DNM2-related centronuclear myopathy: evidence for highly selective muscle involvement. Neuromuscul Disord. 2007; 17:28-32. [PubMed: 17134899]

90. Hanisch F, Muller T, Dietz A, et al. Phenotype variability and histopathological findings in centronuclear myopathy due to DNM2 mutations. J Neurol. 2011; 258:1085-90. [PubMed: 21221624]

91. Kenniston JA, Lemmon MA. Dynamin GTPase regulation is altered by PH domain mutations found in centronuclear myopathy patients. EMBO J. 2010; 29:3054-67. [PubMed: 20700106]

92. Wang L, Barylko B, Byers C, et al. Dynamin 2 mutants linked to centronuclear myopathies form abnormally stable polymers. J Biol Chem. 2010; 285:22753-7. [PubMed: 20529869]

93. Durieux AC, Vignaud A, Prudhon B, et al. A centronuclear myopathy-dynamin 2 mutation impairs skeletal muscle structure and function in mice. Hum Mol Genet. 2010; 19:4820-36. [PubMed: 20858595]

94. Cowling BS, Toussaint A, Amoasii L, et al. Increased expression of wild-type or a centronuclear myopathy mutant of dynamin 2 in skeletal muscle of adult mice leads to structural defects and muscle weakness. Am J Pathol. 2011; 178:2224-35. [PubMed: 21514436]

95. Takei K, Slepnev VI, Haucke V, et al. Functional partnership between amphiphysin and dynamin in clathrin-mediated endocytosis. Nat Cell Biol. 1999; 1:33-9. [PubMed: 10559861]

96. Jungbluth H, Wallgren-Pettersson C, Laporte J. Centronuclear (myotubular) myopathy. Orphanet J Rare Dis. 2008; 3:26. http://www.ojrd.com/content/. [PubMed: 18817572]

97. Lee E, Marcucci M, Daniell L, et al. Amphiphysin 2 (Bin1) and T-tubule biogenesis in muscle. Science. 2002; 297:1193-6. [PubMed: 12183633]

98. Razzaq A, Robinson IM, McMahon HT, et al. Amphiphysin is necessary for organization of the excitation-contraction coupling machinery of muscles, but not for synaptic vesicle endocytosis in Drosophila. Genes Dev. 2001; 15:2967-2979. [PubMed: 11711432]

99. Nicot AS, Toussaint A, Tosch V, et al. Mutations in amphiphysin 2 (BIN1) disrupt interaction with dynamin 2 and cause autosomal recessive centronuclear myopathy. Nat Genet. 2007; 39:1134-9. [PubMed: 17676042]

100••. Toussaint A, Cowling BS, Hnia K, et al. Defects in amphiphysin 2 (BIN1) and triads in several forms of centronuclear myopathies. Acta Neuropathol. 2011; 121:253-66. This article demonstrates that all three mutations involved in myopathies with central nuclei have a common mechanism of pathogenicity involving disruption of T-tubule architecture and function. [PubMed: 20927630]

101. North, K.; Ryan, M. [Accessed January 16, 2010] Nemaline myopathy. GeneReviews at GeneTests: Medical Genetics Information Resource. http://www.genetests.org. Updated October 21,2010

102. Malicdan, MC.; Nishino, I. [Accessed January 16, 2012] Central core disease. GeneReviews at GeneTests: Medical Genetics Information Resource. http://www.genetests.orgUpdated May 11, 2010

Curr Neurol Neurosci Rep. Author manuscript; available in PMC 2015 July 05. 
103. Das, S.; Dowling, J.; Pierson, C. [Accessed January 16. 2012] X-Linked centronuclear myopathy. GeneReviews at GeneTests: Medical Genetics Information Resource. http://www.genetests.org. Updated October 6, 2011

104. Jungbluth H, Wallgren-Pettersson C, Laporte J. Centronuclear (myotubular) myopathy. Orphanet J Rare Dis. 2008; 3:26. http://www.plosone.org/. [PubMed: 18817572]

105. de Haan A, van der Vliet MR, Gommans IM, et al. Skeletal muscle of mice with a mutation in slow alpha-tropomyosin is weaker at lower lengths. Neuromuscul Disord. 2002; 12:952-7. [PubMed: 12467751]

106. Hirata H, Watanabe T, Hatakeyama J, et al. Zebrafish relatively relaxed mutants have a ryanodine receptor defect, show slow swimming and provide a model of multi-minicore disease. Development. 2007; 134:2771-81. [PubMed: 17596281] 


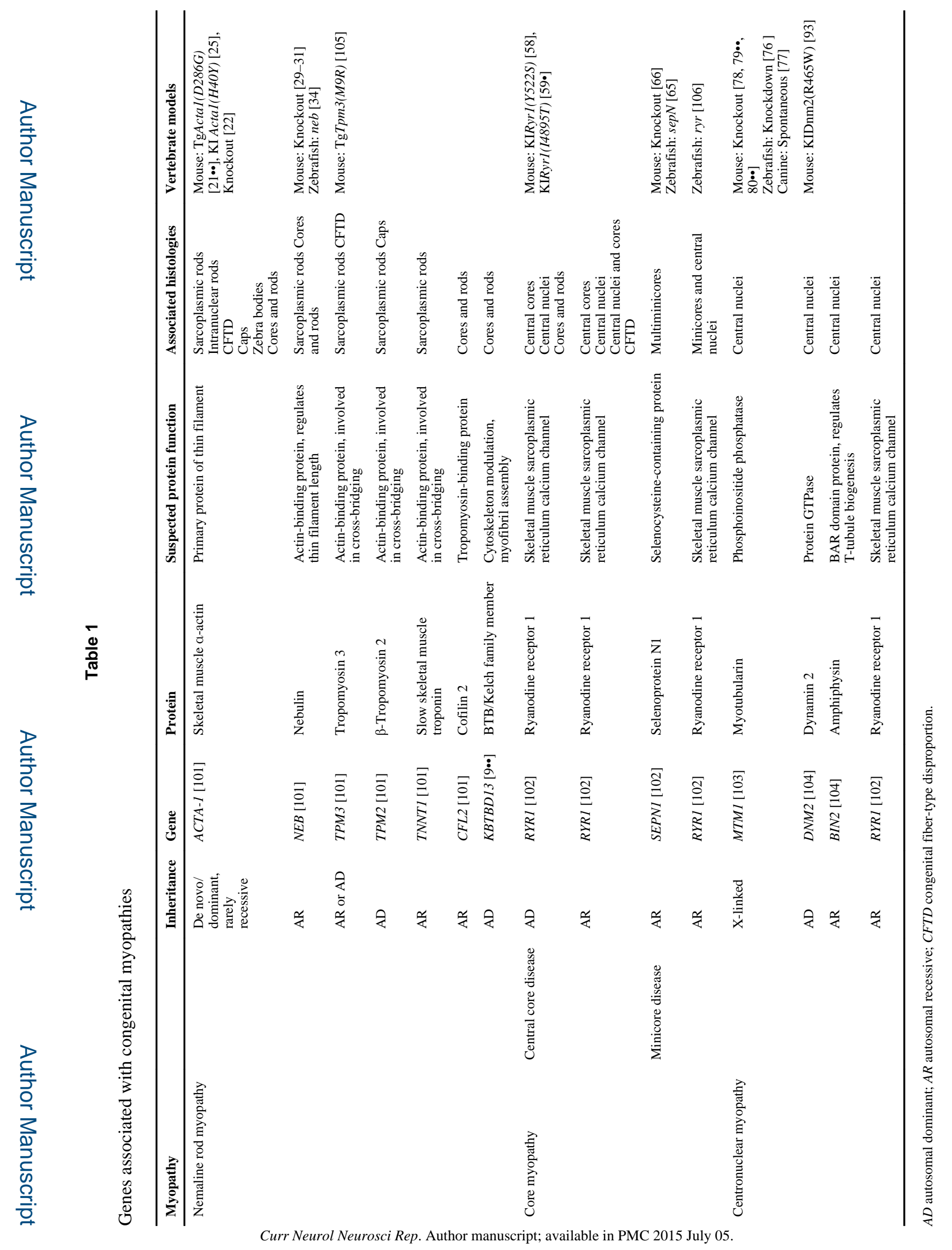

